\title{
DR. E. F. JACOBI - VALEDICTORY NOTICE
}

by

JAN H. STOCK

Dr. Ernst Frederik Jacobi, who was a member of the Editorial Board of this journal for exactly 20 years, reached the age of 65 on September 11 , 1973 and retired.

Dr. Jacobi was appointed Director of the Amsterdam Zoo (officially: of the Royal Zoological Society "Natura Artis Magistra") on April 1, 1953, in succession to Dr. A. L. J. Sunier. The function of Director of the Zoo automatically means also the membership of the Editorial Board of "Bijdragen tot de Dierkunde". This periodical was published by the Royal Zoological Society until vol. 28 of 1949 (the last volume edited by Dr. Jacobi's predecessor), but owing to the difficult financial situation of the Society, its publication was interrupted from 1949 to 1959 , when vol. 29 appeared. From this volume onward, the "Bijdragen" appeared at regular periods, first once a year, later twice a year; also, the periodical was no longer published by the Royal Zoological Society solely, but by a committee (called so beautifully the "Board of Supervisors on the Management of the Artis Library", the Artis Library being the library of the Society, though since 1938 chiefly managed by the University of Amsterdam).

It was Dr. Jacobi who was the first secretary of the Editorial Board of the "Bijdragen" in its new conception; not only he managed to have the journal appear at regular intervals, but there was also a change from one printing firm to another, and a change in format. In the difficult first years of the "Bijdragen" new style, Dr. Jacobi negotiated a joint-volume (1960) with a geological periodical, thus avoiding a budgetary crisis. After these first revival years, the budget became stabilized through regular subventions of the University of Amsterdam and smaller ones of the Royal Zoological Society.
On October 1, 1973, Dr. Jacobi bade the Royal Zoological Society farewell. He was succeeded by Dr. B. M. Lensink, who will be on the Editorial Board from the present volume onward.

The co-editors of "Bijdragen tot de Dierkunde" like to express their gratitude towards Dr. Jacobi for everything he has done for the journal in the past 20 years; in the period of his membership of the Editorial Board, the circulation of the "Bijdragen" increased with a factor 30 and a good part of this increase we owe no doubt to Dr. Jacobi's efforts.

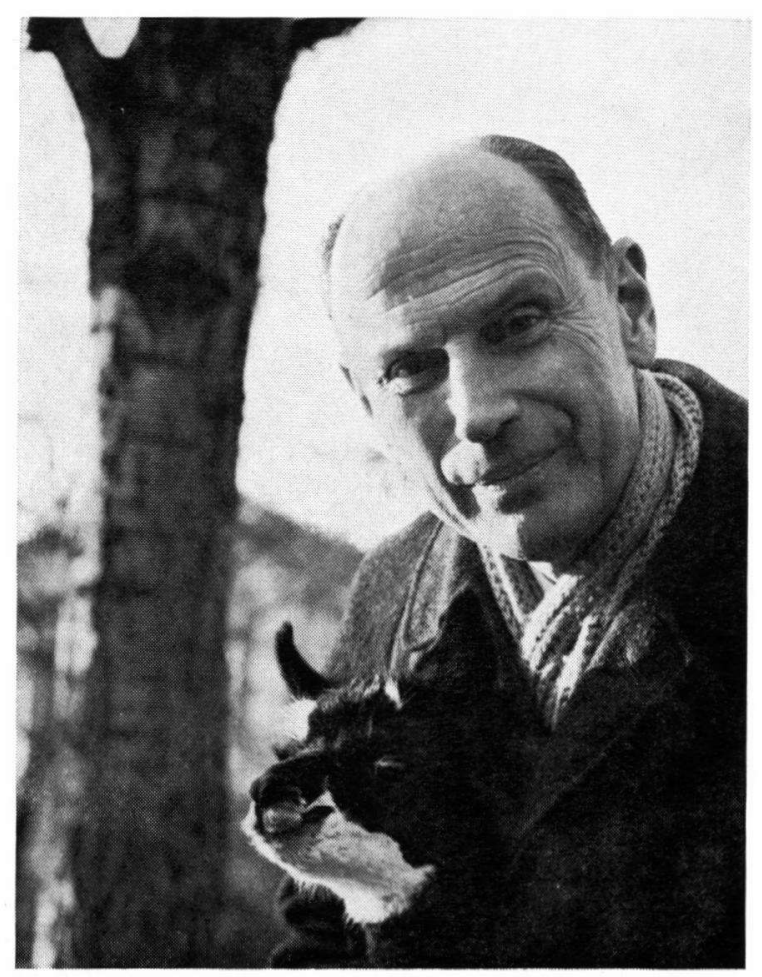

